\title{
Fos Expression in Orexin Neurons Varies with Behavioral State
}

\author{
Ivy V. Estabrooke, ${ }^{1}$ Marie T. McCarthy, ${ }^{1}$ Emily Ko, ${ }^{2}$ Thomas C. Chou, ${ }^{3}$ Richard M. Chemelli, ${ }^{4}$ \\ Masashi Yanagisawa, ${ }^{4}$ Clifford B. Saper, ${ }^{1,3}$ and Thomas E. Scammell ${ }^{1}$ \\ 1Department of Neurology, Beth Israel Deaconess Medical Center, Boston, Massachusetts 02115, 2Department of \\ Psychology, Harvard University, Cambridge, Massachusetts 02138, 3Program in Neuroscience, Harvard Medical School, \\ Boston, Massachusetts 02115, and ${ }^{4}$ Department of Molecular Genetics, University of Texas Southwestern Medical \\ Center, Dallas, Texas 75235
}

The neuropeptide orexin (also known as hypocretin) is hypothesized to play a critical role in the regulation of sleep-wake behavior. Lack of orexin produces narcolepsy, which is characterized by poor maintenance of wakefulness and intrusions of rapid eye movement (REM) sleep or REM sleep-like phenomena into wakefulness. Orexin neurons heavily innervate many aminergic nuclei that promote wakefulness and inhibit REM sleep. We hypothesized that orexin neurons should be relatively active during wakefulness and inactive during sleep. To determine the pattern of activity of orexin neurons, we recorded sleep-wake behavior, body temperature, and locomotor activity under various conditions and used double-label immunohistochemistry to measure the expression of Fos in orexin neurons of the perifornical region. In rats maintained on a $12 \mathrm{hr}$ light/ dark cycle, more orexin neurons had Fos immunoreactive nu-

The neuropeptide orexin (also known as hypocretin) is hypothesized to play a critical role in the regulation of wakefulness and sleep. Orexin is synthesized in neurons of the perifornical region and lateral hypothalamic area, and orexin fibers innervate brain regions known to regulate behavioral state such as the raphe nuclei, the locus coeruleus, the tuberomammillary nucleus, and the cholinergic neurons of the basal forebrain and pons (Peyron et al., 1998; Chemelli et al., 1999; Date et al., 1999). Orexin increases the firing rate of postsynaptic neurons via OX1 and OX2 receptors (Sakurai et al., 1998; Hagan et al., 1999). Recent observations demonstrate that impaired orexin transmission may result in narcolepsy, which is characterized by poor maintenance of wakefulness and intrusions of rapid eye movement (REM) sleep or REM sleep-like phenomena into wakefulness (for review, see Siegel, 1999). The brains of narcoleptics exhibit a nearly complete loss of neurons expressing orexin mRNA or peptide (Peyron et al., 2000; Thannickal et al., 2000), and individuals with narcolepsy often have unmeasurably low orexin levels in CSF (Nishino et al., 2000). Canine narcolepsy is caused by mutations of the OX2 receptor (Lin et al., 1999), and orexin knock-out mice have a phenotype very similar to canine and human narcolepsy (Chemelli et al., 1999). Additionally, the wakefulness produced

\footnotetext{
Received Sept. 1, 2000; revised Nov. 27, 2000; accepted Dec. 11, 2000.

This study was supported by United States Public Health Service Grants MH01507 and HL60292. We are grateful to Janet Mullington for her advice on statistics, Stephanie Gaus for help with preliminary experiments, and Courtney Sears for excellent technical assistance.

Correspondence should be addressed to Dr. Thomas E. Scammell, Department of Neurology, Beth Israel Deaconess Medical Center, 77 Avenue Louis Pasteur, Boston, MA 02115. E-mail: tscammel@caregroup.harvard.edu.

Copyright (C) 2001 Society for Neuroscience 0270-6474/01/211656-07\$15.00/0
}

clei during the night period; in animals housed in constant darkness, this activation still occurred during the subjective night. Sleep deprivation or treatment with methamphetamine also increased Fos expression in orexin neurons. In each of these experiments, Fos expression in orexin neurons correlated positively with the amount of wakefulness and correlated negatively with the amounts of non-REM and REM sleep during the preceding $2 \mathrm{hr}$. In combination with previous work, these results suggest that activation of orexin neurons may contribute to the promotion or maintenance of wakefulness. Conversely, relative inactivity of orexin neurons may allow the expression of sleep.

Key words: orexin; hypocretin; Fos; wake; wakefulness; sleep; REM; lateral hypothalamus; perifornical region; hypothalamus; thermoregulation; rat by modafinil, a drug used to treat the excessive sleepiness of narcolepsy in humans, is accompanied by increased orexin neuron activity in rodents as indicated by increased expression of the transcription factor Fos (Chemelli et al., 1999; Scammell et al., 2000). These observations suggest that orexin may be necessary for the maintenance of wakefulness and the suppression of REM sleep, but the relationship of orexin neuron activity to behavioral state is unknown.

We hypothesized that orexin neurons should be most active during wakefulness and least active during sleep. Extracellular recordings of the perifornical area and lateral hypothalamus would be difficult to interpret because the orexin neurons are intermingled with many other populations. Therefore, we used double immunohistochemical staining for Fos and orexin in combination with physiological recordings of sleep-wake behavior to investigate the relationship between orexin neuron activity and behavioral state in rats.

\section{MATERIALS AND METHODS}

\section{Experimental design}

We performed three experiments to determine whether orexin neuron activity varies with behavioral state. In each experiment, rats were instrumented for electroencephalogram (EEG) and electromyogram (EMG) recordings, as well as the telemetric measurement of locomotor activity (LMA) and body temperature $\left(T_{\mathrm{b}}\right)$. After the experiments, the rats were perfused, and the brain sections were stained for Fos and orexin using double immunohistochemistry. Each experimental group contained six to eight animals.

Experiment 1. To determine whether the activity of orexin neurons changes with circadian variations in sleep-wake behavior, animals were maintained on a $12 \mathrm{hr}$ light/dark (LD) cycle and killed at zeitgeber times (ZTs, in hours) 3, 9, 15, or 21; ZT 0 is morning light onset. To eliminate 
photic influences, two additional groups of rats were kept in constant darkness (DD) for $4 \mathrm{~d}$ and then killed at circadian times (CTs) 3 or 15; CT 0 is the circadian phase at which lights would normally turn on.

Experiment 2. To determine whether orexin neurons are more active during the wakefulness induced by stimulants, we treated rats with methamphetamine or vehicle at ZT 17 and killed the rats $2 \mathrm{hr}$ later.

Experiment 3. To determine whether the wake-related activity of orexin neurons is influenced by the time of day, we deprived rats of sleep for $2 \mathrm{hr}$, from ZT 5 to ZT 7 or ZT 17 to ZT 19, and then killed them. Very dim light (0.35 lux) was maintained during the nighttime sleepdeprivation experiments to allow observation of the animals. Sleep deprivation was performed by tapping lightly on the rats' cages. When light tapping did not awaken the animals, crumpled paper was inserted into the cages to stimulate the rats. If needed, louder tapping of the cage was repeated. The number of stimuli applied during the nighttime sleep deprivation was equivalent to that applied during the day. Separate groups of unhandled control rats were killed at ZT 7 and ZT 19.

\section{Animals and surgery}

Seventy-eight male, Sprague Dawley rats (Harlan) weighing 270-330 gm were housed individually in a pathogen-free barrier facility maintained at 21.5-22.5 ${ }^{\circ} \mathrm{C}$ with lights on at 7:00 A.M. and off at 7:00 P.M. Rats had food and water available ad libitum. Under chloral hydrate anesthesia (350 $\mathrm{mg} / \mathrm{kg}$, i.p.), each animal was surgically implanted with four EEG screws (anteroposterior: $+3,-4$; lateral: $+2,-2$, from bregma) lightly contacting the dura, and EMG wires (Plastics One, Roanoke, VA) were placed in the nuchal muscles. All leads were connected to a six-channel connector (Plastics One) and affixed to the skull with dental acrylic. A telemetric temperature-activity transmitter (TA10TA-F40; Data Sciences International, St. Paul, MN) was placed in the peritoneal cavity. In experiment 2, we administered drugs via an $80 \mathrm{~cm}$ SILASTIC catheter $(1 \mathrm{~mm}$, inner diameter; Baxter Scientific, Boston, MA) to avoid stress caused by handling. The catheter was implanted in the peritoneal cavity, tunneled subcutaneously to the scalp, cemented in place with dental acrylic, and protected externally by a spring. This intraperitoneal catheter was filled with sterile heparinized saline and flushed weekly and $3 \mathrm{~d}$ before the experiment. All animals recovered for at least $14 \mathrm{~d}$ and were allowed to acclimate to commutators for at least $3 \mathrm{~d}$ before the start of physiological recordings. The Institutional Animal Care and Use Committees of Beth Israel Deaconess Medical Center and Harvard Medical School approved all procedures.

For experiment 2, methamphetamine $\mathrm{HCl}$ (U.S. Pharmacopeia, Rockville, MD) was suspended in a solution of $0.25 \%$ methylcellulose (Dow Chemical, Midland, MI), pH 7.4, in 0.9\% pyrogen-free saline (Sigma, St. Louis, MO). Methamphetamine $(0.5 \mathrm{mg} / \mathrm{kg})$ or methylcellulose control vehicle was administered in a volume of $0.7 \mathrm{ml}$ via the chronic intraperitoneal catheter. Catheters were then flushed with $1 \mathrm{ml}$ of $0.9 \%$ saline to guarantee that all of the drug was flushed into the peritoneal cavity, and animals were killed $2 \mathrm{hr}$ later.

\section{Physiological recordings}

EEG and EMG signals were recorded from all animals. These signals were amplified using Grass model 12 amplifiers and digitally acquired using ICELUS software (Mark Opp, University of Texas at Galveston, Galveston, TX). EEG signals were amplified $5000 \times$, bandpass filtered at $0.3-30 \mathrm{~Hz}$, and sampled at $128 \mathrm{~Hz}$. EMG signals were amplified 5000×, bandpass-filtered at $10-100 \mathrm{~Hz}$, sampled at $128 \mathrm{~Hz}$, and integrated into $1 \mathrm{sec}$ values. Behavioral states were scored as wake, non-REM (NREM), or REM in $12 \mathrm{sec}$ epochs by a single examiner who was blinded to the treatment condition. $T_{\mathrm{b}}$ and LMA were monitored every 5 min using Dataquest software (Data Sciences International) and integrated into 30 min intervals. The animals of experiment 1 that were housed in constant darkness for $4 \mathrm{~d}$ had a free-running period of $24 \mathrm{hr}$ in their $T_{\mathrm{b}}$ rhythm, and their $T_{\mathrm{b}}$ minima occurred within $10 \mathrm{~min}$ of the minima of rats housed in LD conditions as determined by cosinor analysis. Telemetric measures of LMA varied considerably between animals, and thus LMA was normalized for each animal by dividing by the mean LMA over the $24 \mathrm{hr}$ before the experiment. Because orexin neurons have been hypothesized to play a role in thermoregulation, we also calculated the change in $T_{\mathrm{b}}$ over the $2 \mathrm{hr}$ before death by subtracting the mean $T_{\mathrm{b}}$ in the second hour before death from the mean temperature over the hour before death. $T_{\mathrm{b}}$ and LMA data from one CT 3 rat of experiment 1 were excluded from analysis because of a malfunctioning transmitter.

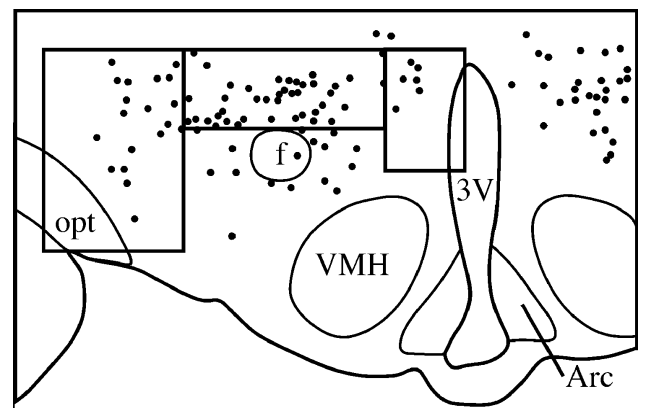

Figure 1. Camera lucida drawing illustrating the cell counting box in the perifornical region. In experiment 1 , cells also were counted within boxes that sampled the lateral hypothalamic area and the area medial to the perifornical region. $V M H$, Ventromedial hypothalamic nucleus; Arc, arcuate hypothalamic nucleus; $f$, fornix; opt, optic tract; $3 V$, third ventricle. Each dot represents an orexin-IR neuron.

\section{Histology and immunohistochemistry}

Animals were anesthetized deeply with chloral hydrate $(700 \mathrm{mg} / \mathrm{kg}$, i.p.) and perfused transcardially with $100 \mathrm{ml}$ of $0.9 \%$ saline and $500 \mathrm{ml}$ of phosphate-buffered 10\% formalin, pH 7.0 (Sigma). Brains were removed, post-fixed for $4 \mathrm{hr}$ in formalin, and then allowed to equilibrate in $20 \%$ sucrose in $0.1 \mathrm{M}$ PBS with $0.02 \%$ sodium azide (Sigma). Brains were then sectioned $(1: 5$ series, $30 \mu \mathrm{m})$ on a freezing microtome and stored in PBS-azide at $4^{\circ} \mathrm{C}$. Hypothalamic sections were selected from one series of each brain and stained immunohistochemically for Fos using previously described methods (Elmquist et al., 1996). Briefly, tissue was incubated in rabbit anti-Fos antiserum (Ab-5, 1:100,000) (Oncogene Research Products, Cambridge, MA) for $48 \mathrm{hr}$ with $3 \%$ normal donkey serum (Jackson ImmunoResearch, West Grove, PA). A biotinylated donkey anti-rabbit secondary antiserum (Jackson ImmunoResearch) was used at a dilution of 1:1000. Tissue was then reacted with avidin-biotin complex (Vectastain ABC Elite kit; Vector Laboratories, Burlingame, CA) for $1 \mathrm{hr}$, and Fos-immunoreactive (IR) nuclei were visualized by reaction with 3,3'-diaminobenzidine (DAB; Sigma), $3 \% \mathrm{H}_{2} \mathrm{O}_{2}, 0.01 \%$ $\mathrm{NiSO}_{4}$, and $0.01 \% \mathrm{CoCl}_{2}$. After Fos staining, sections were rinsed in PBS-azide and incubated overnight in rabbit anti-orexin-A primary antiserum (1:5000) (M. Yanagisawa, University of Texas Southwestern Medical Center) and 3\% normal donkey serum (Jackson ImmunoResearch). Sections were then incubated for $2 \mathrm{hr}$ in donkey anti-rabbit secondary antiserum (1:500) (Jackson ImmunoResearch) and 3\% normal donkey serum. The staining was completed as described above with the exclusion of the $\mathrm{NiSO}_{4} / \mathrm{CoCl}_{2}$ in the DAB step to yield a brown cytoplasmic product in orexin-IR neurons. The orexin antiserum used in experiment 2 was a different lot than that used in experiments 1 and 3 . The orexin immunostaining was blocked by preadsorption with $50 \mu \mathrm{g} / \mathrm{ml}$ of orexin-A, and omission of the primary antiserum resulted in no specific staining. The Fos antiserum was previously characterized in our laboratory (Elmquist et al., 1996).

\section{Cell counts}

A single examiner, who was blinded to treatment conditions, performed all counts using a Leitz Laborlux microscope. Perifornical Fos-IR nuclei, orexin-IR neurons, and double-labeled neurons were counted in sections beginning $300 \mu \mathrm{m}$ behind the paraventricular nucleus of the hypothalamus using a horizontally oriented $1 \times 0.4 \mathrm{~mm}$ box centered just dorsal to the fornix (Fig. 1). Cells were counted on both sides of the brain in three consecutive sections $150 \mu \mathrm{m}$ apart. The six counts per animal were then averaged. Although the orexin neurons are concentrated in the perifornical region, the number of orexin neurons within the counting box varied by as much as a factor of two between animals. To correct for this variation in sampling of orexin neurons, we calculated the percentage of double-labeled cells for each animal (double-labeled neurons/orexin-IR neurons) as a measure of orexin neuron activity. Fos expression was not limited to the orexin-IR neurons, and we defined these as "Fos-IR, non-orexin-IR" neurons, although some non-orexin-IR neurons may simply have orexin concentrations below our detection limit. In experiment 1 , cells also were counted in the region medial to the perifornical counting box using a vertically oriented $0.4 \times 0.6 \mathrm{~mm}$ box and in the lateral hypothalamic area using a vertically oriented $0.7 \times 1.0 \mathrm{~mm}$ box; 
Table 1. Perifornical region cell counts, sleep-wake behavior, $T_{b}$, and LMA of rats killed at different times under LD or DD conditions

\begin{tabular}{|c|c|c|c|c|c|c|c|c|}
\hline & \multicolumn{5}{|l|}{ LD } & \multicolumn{3}{|l|}{ DD } \\
\hline & ZT 3 & ZT 9 & ZT 15 & ZT 21 & $\begin{array}{l}\text { Kruskal-Wallis } \\
p \text { value }\end{array}$ & CT 3 & CT 15 & $\begin{array}{l}\text { Mann-Whitney } \\
p \text { value }\end{array}$ \\
\hline$n$ & 6 & 7 & 6 & 7 & & 6 & 6 & \\
\hline Fos-IR neurons & $31 \pm 4$ & $44 \pm 8$ & $80 \pm 7$ & $72 \pm 5$ & 0.001 & $25 \pm 5$ & $60 \pm 6$ & 0.007 \\
\hline Orexin-IR neurons & $79 \pm 5$ & $80 \pm 3$ & $71 \pm 5$ & $74 \pm 3$ & N.S. & $83 \pm 4$ & $80 \pm 2$ & N.S. \\
\hline Double-labeled neurons & $15 \pm 2$ & $19 \pm 5$ & $32 \pm 5$ & $36 \pm 2$ & 0.009 & $7 \pm 3$ & $26 \pm 3$ & 0.007 \\
\hline Non-orexin-IR, Fos-IR neurons & $16 \pm 4$ & $25 \pm 4$ & $47 \pm 5$ & $36 \pm 3$ & 0.001 & $18 \pm 4$ & $34 \pm 3$ & 0.03 \\
\hline$\%$ Wake & $38.1 \pm 12.9$ & $46.6 \pm 4.0$ & $71.7 \pm 5.4$ & $72.6 \pm 7.4$ & 0.008 & $38.3 \pm 8.4$ & $79.9 \pm 3.5$ & 0.007 \\
\hline$\%$ NREM sleep & $53.1 \pm 10.7$ & $46.6 \pm 3.7$ & $23.3 \pm 4.0$ & $25 \pm 6.7$ & 0.01 & $52.6 \pm 6.8$ & $18.6 \pm 3.0$ & 0.007 \\
\hline$\%$ REM sleep & $8.8 \pm 3.6$ & $6.8 \pm 1.4$ & $5.0 \pm 1.6$ & $2.4 \pm 0.9$ & N.S. & $9.2 \pm 3.2$ & $1.5 \pm 0.9$ & 0.05 \\
\hline$T_{\mathrm{b}}\left({ }^{\circ} \mathrm{C}\right)$ & $37.2 \pm 0.1$ & $37.0 \pm 0.1$ & $37.9 \pm 0.1$ & $37.8 \pm 0.1$ & 0.001 & $37.1 \pm 0.1$ & $37.7 \pm 0.1$ & 0.01 \\
\hline Change in $T_{\mathrm{b}}\left({ }^{\circ} \mathrm{C}\right)$ & $-0.1 \pm 0$ & $0.3 \pm 0.1$ & $-0.1 \pm 0$ & $-0.2 \pm 0.2$ & 0.03 & $0.0 \pm 0.1$ & $0.0 \pm 0.1$ & N.S. \\
\hline LMA & $0.3 \pm 0.1$ & $0.6 \pm 0.1$ & $1.5 \pm 0.2$ & $1.4 \pm 0.1$ & 0.0007 & $0.6 \pm 0.1$ & $1.7 \pm 0.2$ & 0.01 \\
\hline
\end{tabular}

Behavior over the 2 hr before death was used to calculate the physiologic measures. Values are means \pm SE. N.S., Not significant. fornical orexin-IR neurons from a rat killed at ZT 3. B, A rat killed at ZT 15 has many Fos-IR nuclei in orexin-IR neurons. Arrow, Orexin-IR neuron; arrowhead, Fos-IR nucleus; double arrow, Fos-IR/ orexin-IR neuron. Scale bar, $50 \mu \mathrm{m}$.
Figure 2. A, Fos-IR nuclei are uncommon in peri-
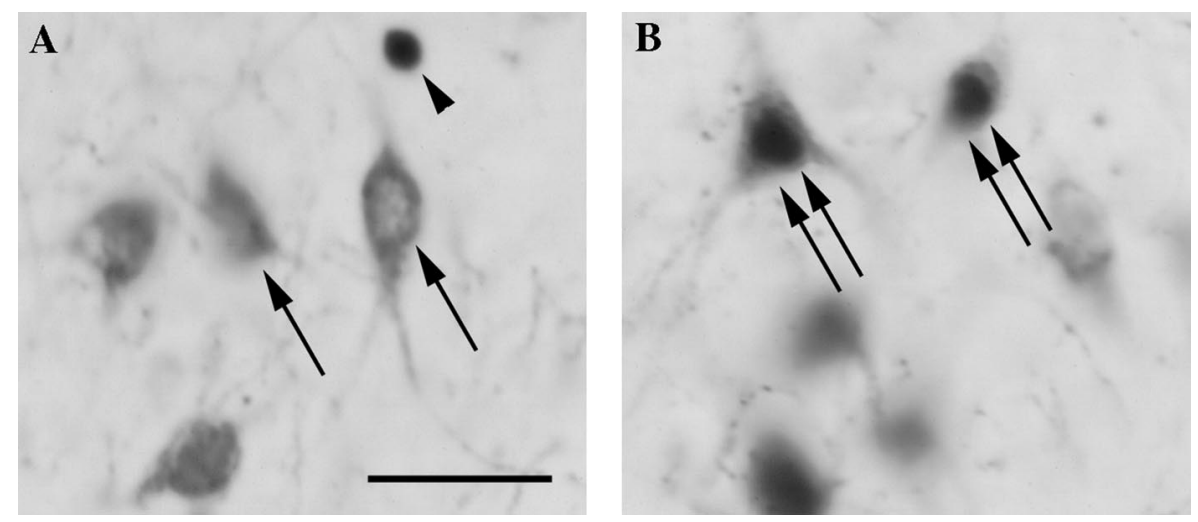

these boxes abutted the edges of the perifornical counting box as shown in Figure 1. Within these medial and lateral areas, orexin neurons are more numerous caudally, so counts in these regions began with the third section on which perifornical counts were performed.

\section{Statistical analysis}

Mann-Whitney or Kruskal-Wallis rank sum tests were used to compare cell counts between groups, and these same tests were used for analysis of physiological variables. In experiments with multiple groups, a post hoc Scheffe test was used to identify significant pairwise differences. Cell counts were not corrected for double-counting errors (Guillery and Herrup, 1997) because there was no change in the size of labeled cells or nuclei across groups, and only relative, not absolute, values were sought. Cell counts were correlated with physiological variables using the Pearson correlation coefficient. In our previous work, we have correlated Fos expression with sleep-wake behavior in the hour before death. In preliminary experiments, we found that orexin neuron activation correlated slightly better with behavior over the $2 \mathrm{hr}$ before death, and this longer interval was used throughout our analyses.

\section{RESULTS}

\section{Experiment 1: circadian variations in orexin neuron activity}

Under LD conditions, the number of double-labeled neurons (orexin-IR neurons with Fos-IR nuclei) varied across the four time points, with higher levels of double-labeling in the two nighttime groups (Table 1, Fig. 2). The percentage of doublelabeled neurons also varied across the four groups $(p<0.0001)$ (Fig. 3), with either of the daytime groups differing from either of the nighttime groups on pairwise comparisons $(p<0.02)$. In addition, the total number of Fos-IR neurons and the number of

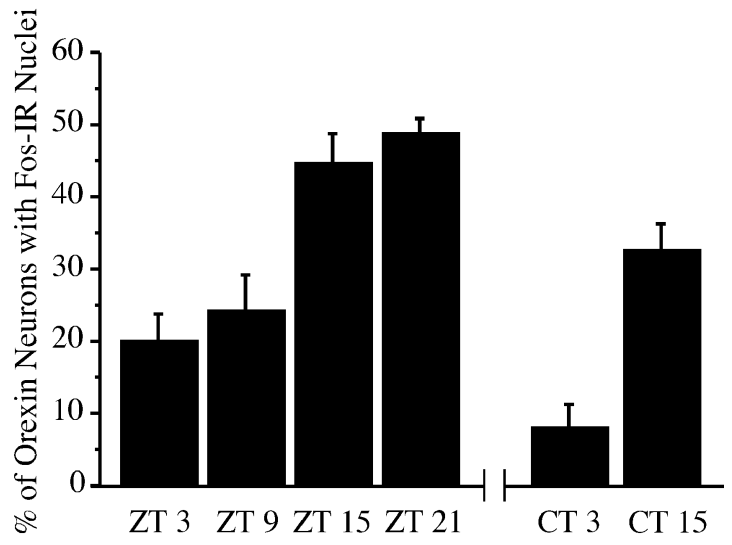

Figure 3. Fos expression in perifornical orexin neurons is higher during the night in rats maintained on a $12 \mathrm{hr}$ LD cycle (ZT 3 through ZT 21 groups). In rats maintained in constant darkness (CT 3 and $C T 15$ groups), the percentage of double-labeling also is higher during the subjective night.

Fos-IR, non-orexin-IR neurons in the perifornical region differed across the four time points, with more Fos-IR neurons in the two nighttime groups. Pairwise differences in the total number of Fos-IR neurons or the number of Fos-IR, non-orexin-IR neurons were evident between either of the daytime groups and either of the nighttime groups $(p<0.01)$, except that the ZT 9 group did not differ from the ZT 21 group.

Animals maintained in constant darkness showed a similar 
Table 2. Correlations of the percentage of double-labeled neurons to sleep-wake behavior, $T_{\mathrm{b}}$, and LMA

\begin{tabular}{|c|c|c|c|c|c|c|c|}
\hline & & Wake & NREM & REM & $T_{\mathrm{b}}$ & $\begin{array}{l}\text { Change in } \\
T_{\mathrm{b}}\end{array}$ & LMA \\
\hline Experiment 1 : circadian variations & $\begin{array}{l}\mathrm{LD} \\
\mathrm{DD}\end{array}$ & $\begin{aligned} r & =0.62 \\
p & =0.0006 \\
r & =0.86 \\
p & =0.0001\end{aligned}$ & $\begin{aligned} r & =-0.59 \\
p & =0.001 \\
r & =-0.87 \\
p & <0.0001\end{aligned}$ & $\begin{aligned} r & =-0.52 \\
p & =0.006 \\
r & =-0.56 \\
p & =0.05\end{aligned}$ & $\begin{aligned} r & =0.83 \\
p & <0.0001 \\
r & =0.82 \\
p & =0.005\end{aligned}$ & $\begin{aligned} r & =-0.25 \\
p & =\mathrm{N} . \mathrm{S} . \\
r & =0.33 \\
p & =\mathrm{N} . \mathrm{S} .\end{aligned}$ & $\begin{aligned} r & =0.86 \\
p & <0.0001 \\
r & =0.81 \\
p & =0.005\end{aligned}$ \\
\hline Experiment 2: methamphetamine & & $\begin{aligned} r & =0.8 \\
p & =0.0005\end{aligned}$ & $\begin{aligned} r & =-0.8 \\
p & =0.0005\end{aligned}$ & $\begin{aligned} r & =-0.72 \\
p & =0.004\end{aligned}$ & $\begin{array}{l}r=-0.13 \\
p=\mathrm{N} . \mathrm{S} .\end{array}$ & $\begin{array}{l}r=-0.51 \\
p=\text { N.S. }\end{array}$ & $\begin{array}{l}r=0.62 \\
p=\text { N.S. }\end{array}$ \\
\hline Experiment 3: sleep deprivation & $\begin{array}{l}\text { Daytime } \\
\text { Nighttime }\end{array}$ & $\begin{aligned} r & =0.97 \\
p & <0.0001 \\
r & =0.43 \\
p & =\text { N.S. }\end{aligned}$ & $\begin{array}{c}r=-0.97 \\
p<0.0001 \\
r=-0.45 \\
p=\text { N.S. }\end{array}$ & $\begin{aligned} r & =-0.88 \\
p & <0.0001 \\
r & =-0.24 \\
p & =\text { N.S. }\end{aligned}$ & $\begin{aligned} r & =0.96 \\
p & <0.0001 \\
r & =-0.32 \\
p & =\text { N.S. }\end{aligned}$ & $\begin{aligned} r & =0.54 \\
p & =0.03 \\
r & =0.39 \\
p & =\text { N.S. }\end{aligned}$ & $\begin{aligned} r & =0.88 \\
p & <0.0001 \\
r & =-0.17 \\
p & =\text { N.S. }\end{aligned}$ \\
\hline
\end{tabular}

increase in the percentage of double-labeled neurons during the subjective night $(p=0.007)$. The total number of Fos-IR neurons and the number of Fos-IR, non-orexin-IR neurons also were higher during the subjective night. Comparison of the LD and DD groups revealed no differences in the number of Fos-IR neurons, orexin-IR neurons, or Fos-IR, non-orexin-IR neurons at CT 3 versus ZT 3, although the percentage of double-labeled neurons was slightly decreased $(p=0.02)$. The CT 15 and ZT 15 groups did not differ in any of these measures.

During the $2 \mathrm{hr}$ before death, the amounts of wakefulness were higher in the two LD nighttime groups compared with the daytime groups, and this pattern persisted in the DD groups. Higher $T_{\mathrm{b}}$ and greater LMA accompanied this increased wakefulness during the (subjective) night. The change in $T_{\mathrm{b}}$ over the final $2 \mathrm{hr}$ did not differ between groups. Under LD conditions, the percentage of double-labeled cells correlated positively with the amount of wakefulness and negatively with the amounts of NREM and REM sleep (Table 2). The percentage of double-labeled cells also correlated with $T_{\mathrm{b}}$ and LMA but not with the change in $T_{\mathrm{b}}$ over the $2 \mathrm{hr}$ before death. These relationships persisted in constant darkness.

To determine whether this pattern of wake-related Fos was evident in all orexin neurons, we counted cells in the perifornical, medial, and lateral parts of the orexin field. Compared with rats killed at ZT 3, rats killed at ZT 15 had a greater percentage of Fos-IR, orexin-IR neurons within the medial and perifornical regions, but no diurnal variation was evident in the lateral region (Fig. 4).

\section{Experiment 2: orexin neuron activity during treatment with methamphetamine}

Rats treated with methamphetamine had a greater percentage of double-labeled neurons compared with controls ( $p=0.003)$ (Fig. 5 ). Fos expression in perifornical non-orexin-IR neurons was also increased, although the number of orexin-IR neurons did not differ (Table 3).

Methamphetamine-treated animals were significantly more awake in the $2 \mathrm{hr}$ between injection and death (ZT 17 to ZT 19) than control animals. This increased wakefulness was accompanied by a small increase in LMA, but there was no significant difference in $T_{\mathrm{b}}$ or the change in $T_{\mathrm{b}}$ after drug administration. The percentage of double-labeled neurons correlated positively with the amount of wakefulness and negatively with the amounts of NREM and REM sleep. The percentage of double-labeled neurons did not correlate with LMA, $T_{\mathrm{b}}$, or the change in $T_{\mathrm{b}}$.

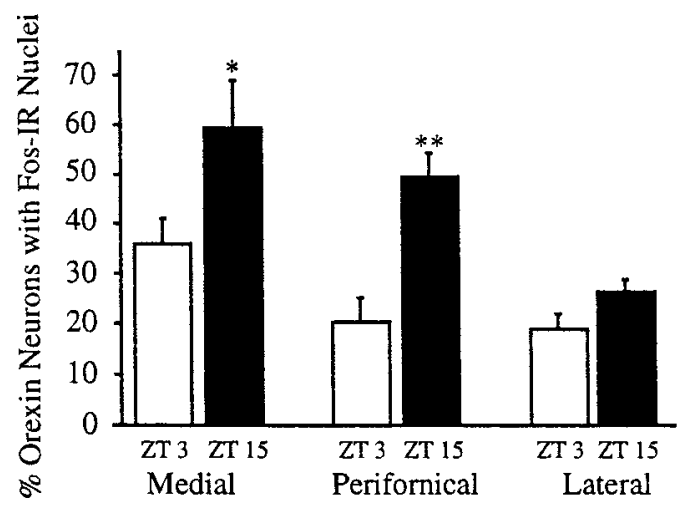

Figure 4. Orexin neurons in the perifornical region have the greatest diurnal variation in Fos expression. Orexin neurons medial to the perifornical region have a less striking diurnal variation, but Fos expression does not vary in orexin neurons of the lateral hypothalamic area. ${ }^{*} p=$ $0.05 ; * * p=0.01$.

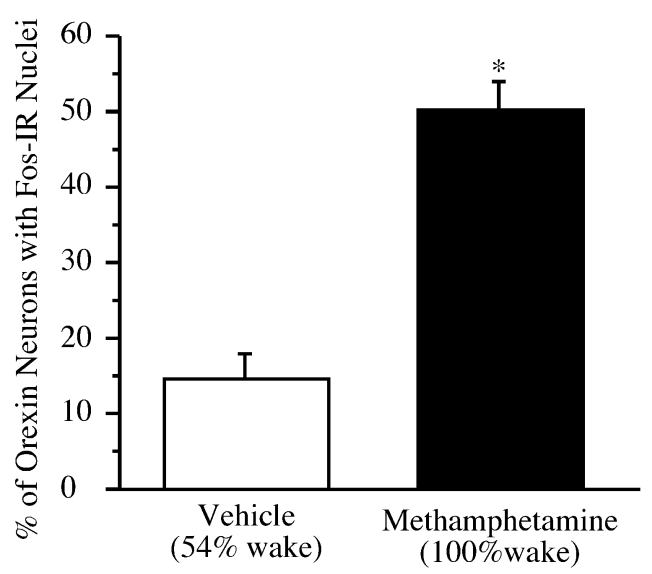

Figure 5. Methamphetamine increases Fos expression in perifornical orexin neurons. ${ }^{*} p=0.003$.

\section{Experiment 3: orexin neuron activity during sleep deprivation}

Animals that were sleep deprived from ZT 5 to ZT 7 had a greater percentage of double-labeled neurons than did the unhandled control rats $(p=0.001)$ (Fig. 6). The number of Fos-IR, non-orexin-IR neurons in the perifornical region also increased with sleep deprivation, although the number of orexin-IR neu- 
Table 3. Perifornical cell counts, sleep-wake behavior, $T_{\mathrm{b}}$, and LMA of animals treated with vehicle or methamphetamine $(0.5 \mathrm{mg} / \mathrm{kg})$ at ZT 17 and killed $2 \mathrm{hr}$ later

\begin{tabular}{lccl} 
& Vehicle & $\begin{array}{c}\text { Metham- } \\
\text { phetamine }\end{array}$ & $\begin{array}{l}\text { Mann-Whitney } \\
p \text { value }\end{array}$ \\
\hline$n$ & 6 & 7 & \\
Fos-IR neurons & $21 \pm 2$ & $59 \pm 3$ & 0.003 \\
Orexin-IR neurons & $47 \pm 5$ & $52 \pm 2$ & N.S. \\
$\begin{array}{l}\text { Double-labeled neurons } \\
\text { Non-orexin-IR, Fos-IR }\end{array}$ & $7 \pm 2$ & $28 \pm 2$ & 0.003 \\
$\quad$ neurons & $14 \pm 1$ & $31 \pm 2$ & 0.003 \\
\% Wake & $53.5 \pm 5.4$ & $100.0 \pm 0.0$ & 0.001 \\
\% NREM sleep & $43.3 \pm 4.9$ & $0.0 \pm 0.0$ & 0.001 \\
$\%$ REM sleep & $3.3 \pm 0.7$ & $0.0 \pm 0.0$ & 0.001 \\
$T_{\mathrm{b}}\left({ }^{\circ} \mathrm{C}\right)$ & $37.9 \pm 0.2$ & $37.8 \pm 0.4$ & $\mathrm{~N} . \mathrm{S}$. \\
Change in $T_{\mathrm{b}}\left({ }^{\circ} \mathrm{C}\right)$ & $0.1 \pm 0.1$ & $0.0 \pm 0.1$ & $\mathrm{~N} . \mathrm{S}$. \\
LMA & $1.1 \pm 0.4$ & $3.0 \pm 0.5$ & 0.03 \\
\hline
\end{tabular}

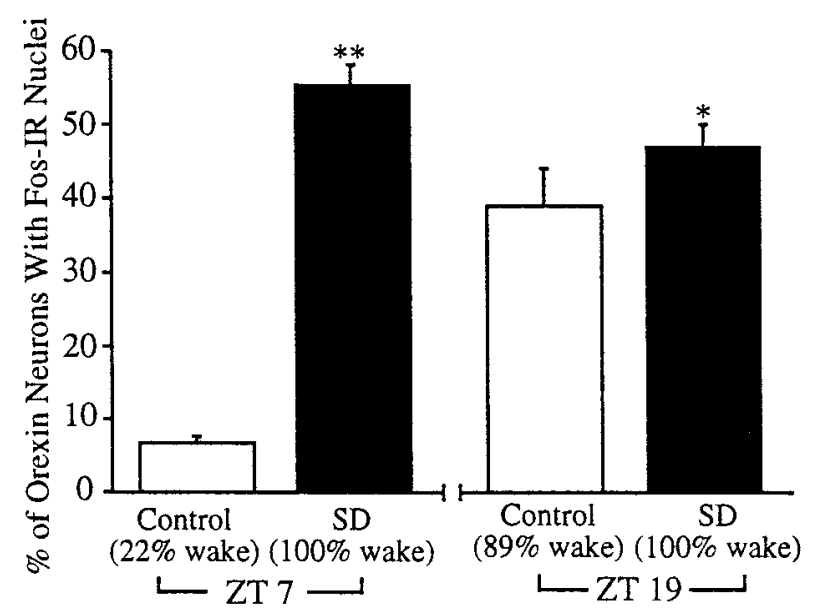

Figure 6. Sleep deprivation from ZT 5 to ZT 7 increases Fos expression in perifornical orexin-IR neurons. Sleep deprivation from ZT 17 to ZT 19 marginally increases Fos immunoreactivity in orexin-IR neurons. * $p=$ $0.04 ; * p<0.0001$.

rons did not change (Table 4). Orexin neuron Fos expression correlated positively with the amounts of wakefulness, LMA, and $T_{\mathrm{b}}$ and negatively with the amounts of NREM and REM sleep.

Sleep deprivation from ZT 17 to ZT 19 produced a small increase in the percentage of double-labeled neurons $(p=0.04)$, but the absolute number of double-labeled neurons was unchanged. The total number of Fos-IR neurons was increased, although there was no difference in the number of orexin-IR neurons. Sleep deprivation modestly increased the amount of wakefulness, but there were no significant differences in $T_{\mathrm{b}}$, change in $T_{\mathrm{b}}$, or LMA between the two groups, and Fos expression in orexin-IR neurons did not correlate with any of these variables.

Across all three experiments, the percentage of double-labeled neurons correlated positively with the amount of wakefulness over the previous $2 \mathrm{hr}(r=0.78 ; p<0.0001)$ and negatively with the amounts of NREM $(r=-0.78 ; p<0.0001)$ and REM sleep $(r=-0.63 ; p<0.0001)$ (Fig. 7). This relation with behavioral state was most evident at the extremes of behavior; rats with $>80 \%$ wakefulness had moderate to large numbers of doublelabeled neurons, whereas those with substantial amounts of
NREM or REM sleep had very few double-labeled cells. To determine the relative contributions of NREM and REM sleep, we performed a stepwise regression analysis which revealed that the percentage of double-labeled neurons was strongly related to the amount of NREM sleep $(r=-0.78$; $p<0.0001)$ with little relation to the amount of REM sleep $(r=-0.09)$ once the effects of NREM were removed. The percentage of double-labeled neurons also correlated well with LMA $(r=0.68 ; p<0.0001)$ and $T_{\mathrm{b}}$ $(r=0.59 ; p<0.0001)$. Although these animals differed in handling, drug administration, ambient light exposure, and time of death, these correlations were evident under all conditions.

\section{DISCUSSION}

We used Fos immunohistochemistry to investigate the relation between orexin neuron activity, behavioral state, $T_{\mathrm{b}}$, and LMA. We found that Fos expression in perifornical orexin neurons was common after periods of wakefulness but uncommon after periods of NREM and REM sleep. Orexin neuron Fos expression exhibited a circadian pattern under both LD and DD conditions; in experiments 1 and 3, this Fos expression also correlated with $T_{\mathrm{b}}$ and LMA.

Several methodological issues warrant discussion. First, Fos is a useful marker of activity in neurochemically defined neurons, often indicating an increase in synaptic activity or a rise in the intracellular concentrations of cAMP or calcium (for review, see Cirelli and Tononi, 2000). Still, Fos immunohistochemistry has some limitations. Fos protein may persist in neurons for several hours after a stimulus (Schwartz et al., 1994), and its presence may reflect the summation of neuronal activity over time. Thus, the correlation of orexin neuron activity with sleep-wake behavior must be interpreted cautiously; for example, although rats with $>15 \%$ REM sleep had especially low levels of Fos expression, these animals often had increases in their total amount of sleep, and we cannot determine whether orexin neurons are inactive during REM sleep in particular. Identifying whether orexin neurons are active during specific bouts of wakefulness or sleep must await techniques with better temporal resolution. In addition, we cannot be certain whether an increase in Fos corresponds to changes in firing rates or the release of transmitters from orexin nerve terminals.

Second, we used a different lot of orexin antiserum in experiment 2 than we used in experiments 1 and 3, and this antiserum consistently labeled fewer orexin neurons per brain section. Although this influenced the absolute counts of orexin-IR neurons, it is unlikely to have substantially biased the results because the percentage of double-labeled neurons after $2 \mathrm{hr}$ of methamphetamine-induced wakefulness was comparable with that seen after $2 \mathrm{hr}$ of sleep deprivation.

Third, many researchers have found that methamphetamine increases $T_{\mathrm{b}}$, especially at high doses, and even $0.5 \mathrm{mg} / \mathrm{kg}$ can produce a rise of $0.3^{\circ} \mathrm{C}$ (Edgar and Seidel, 1997). Although we found that this dose produced increases in LMA and wakefulness similar to those reported by Edgar and Seidel (1997), we did not observe an increase in $T_{\mathrm{b}}$. Most previous studies administered methamphetamine during the day, whereas we gave it at ZT 17, a time when $T_{\mathrm{b}}$ is relatively elevated. Perhaps the hyperthermic effects of methamphetamine were masked by this elevated nighttime $T_{\mathrm{b}}$.

Finally, sleep deprivation can induce stress, particularly when performed during the animal's normal sleep period. Orexin neurons may influence autonomic functions associated with stress, such as increases in pulse, blood pressure, and $T_{\mathrm{b}}$ (Hagan et al., 
Table 4. Perifornical cell counts, sleep-wake behavior, $T_{b}$, and LMA for animals sleep deprived from ZT 5 to ZT 7 and animals sleep deprived from ZT 17 to ZT 19

\begin{tabular}{|c|c|c|c|c|c|c|}
\hline & \multicolumn{3}{|c|}{ Daytime (ZT 5-ZT 7) } & \multicolumn{3}{|c|}{ Nighttime (ZT 17-ZT 19) } \\
\hline & Control & $\begin{array}{l}\text { Sleep } \\
\text { deprived }\end{array}$ & $\begin{array}{l}\text { Mann-Whitney } \\
p \text { values }\end{array}$ & Control & $\begin{array}{l}\text { Sleep } \\
\text { deprived }\end{array}$ & $\begin{array}{l}\text { Mann-Whitney } \\
p \text { values }\end{array}$ \\
\hline$n$ & 7 & 8 & & 6 & 6 & \\
\hline Fos-IR neurons & $25 \pm 4$ & $101 \pm 4$ & 0.001 & $57 \pm 4$ & $79 \pm 6$ & 0.01 \\
\hline Orexin-IR neurons & $81 \pm 3$ & $74 \pm 3$ & N.S. & $80 \pm 3$ & $72 \pm 5$ & N.S. \\
\hline Double-labeled neurons & $5 \pm 1$ & $41 \pm 3$ & 0.001 & $31 \pm 2$ & $34 \pm 3$ & N.S. \\
\hline Non-orexin-IR, Fos-IR neurons & $20 \pm 4$ & $60 \pm 4$ & 0.001 & $26 \pm 3$ & $44 \pm 5$ & 0.007 \\
\hline$\%$ Wake & $21.2 \pm 3.2$ & $99.7 \pm 0.2$ & 0.001 & $89.2 \pm 3.5$ & $100 \pm 0.0$ & 0.002 \\
\hline$\%$ NREM sleep & $62.5 \pm 3.3$ & $0.1 \pm 0.1$ & 0.0006 & $9.2 \pm 2.9$ & $0.0 \pm 0.0$ & 0.002 \\
\hline$\%$ REM sleep & $16.3 \pm 2.2$ & $0.2 \pm 0.2$ & 0.0006 & $1.0 \pm 0.6$ & $0.0 \pm 0.0$ & N.S. \\
\hline$T_{\mathrm{b}}\left({ }^{\circ} \mathrm{C}\right)$ & $36.8 \pm 0.1$ & $37.7 \pm 0.1$ & 0.001 & $37.9 \pm 0.2$ & $38.3 \pm 0.2$ & N.S. \\
\hline Change in $T_{\mathrm{b}}\left({ }^{\circ} \mathrm{C}\right)$ & $0.0 \pm 0.1$ & $0.3 \pm 0.1$ & 0.03 & $0.0 \pm 0.1$ & $0.3 \pm 0.1$ & N.S. \\
\hline LMA & $0.4 \pm 0.1$ & $2.4 \pm 0.2$ & 0.001 & $2.1 \pm 0.1$ & $2.7 \pm 0.5$ & N.S. \\
\hline
\end{tabular}

1999; Samson et al., 1999); therefore it is difficult to ascertain whether the increase in Fos produced by sleep deprivation during the day is related to increased wakefulness or stress. However, stress is unlikely to be a major factor because sleep deprivation during the night did not significantly increase orexin neuron Fos expression compared with unhandled controls, and the amount of handling was comparable with that used during the daytime experiments. Additionally, the animals of experiments 1 and 2 were not handled. Thus, across all experiments, increased wakefulness was the factor most consistently associated with orexin neuron activation.

All three experiments demonstrated a positive correlation between Fos expression in perifornical orexin neurons and the percentage of wakefulness in the $2 \mathrm{hr}$ preceding death. These relationships persisted in constant darkness, indicating that the activity of orexin neurons does not depend on photic stimuli. Orexin neurons also were active in association with the wakefulness produced by methamphetamine, as we have previously shown with the wake-promoting drug modafinil (Chemelli et al., 1999; Scammell et al., 2000). Fos expression in orexin-IR neurons correlated with the amount of wakefulness after daytime sleep deprivation but not after sleep deprivation at night, possibly because the abundant wakefulness in the nighttime control group diminished the contrast between groups. Our analysis of Fos expression in different parts of the orexin field demonstrates that orexin neurons in the perifornical region exhibit more diurnal variation in activity than orexin neurons in the lateral hypothalamic area. Although it is possible that this finding simply reflects a tendency for some orexin neurons to express Fos more readily, it also may indicate a functional heterogeneity across the orexin field. Abrahamson and Moore (1999) have demonstrated that orexin neurons within different parts of the orexin field may project to separate targets, and our results suggest that the perifornical orexin neurons may be involved more closely with the control of sleep-wake behavior. Our experimental design does not allow us to determine whether this orexin neuron activity promotes wakefulness or is a consequence of wakefulness, but these associations demonstrate a consistent relationship between the activity of perifornical orexin neurons and behavioral state. Taheri and colleagues (2000) have demonstrated diurnal variations in prepro-orexin mRNA as well as in the concentration of orexin-A within the preoptic area and pons. This evidence, in conjunction with the finding that intracerebroventricular injection of orexin increases wakefulness (Hagan et al., 1999), suggests that increased orexin neuron activity may contribute to the promotion or maintenance of wakefulness.

Across all of these experiments, perifornical orexin neuron activity was negatively correlated with the amounts of NREM
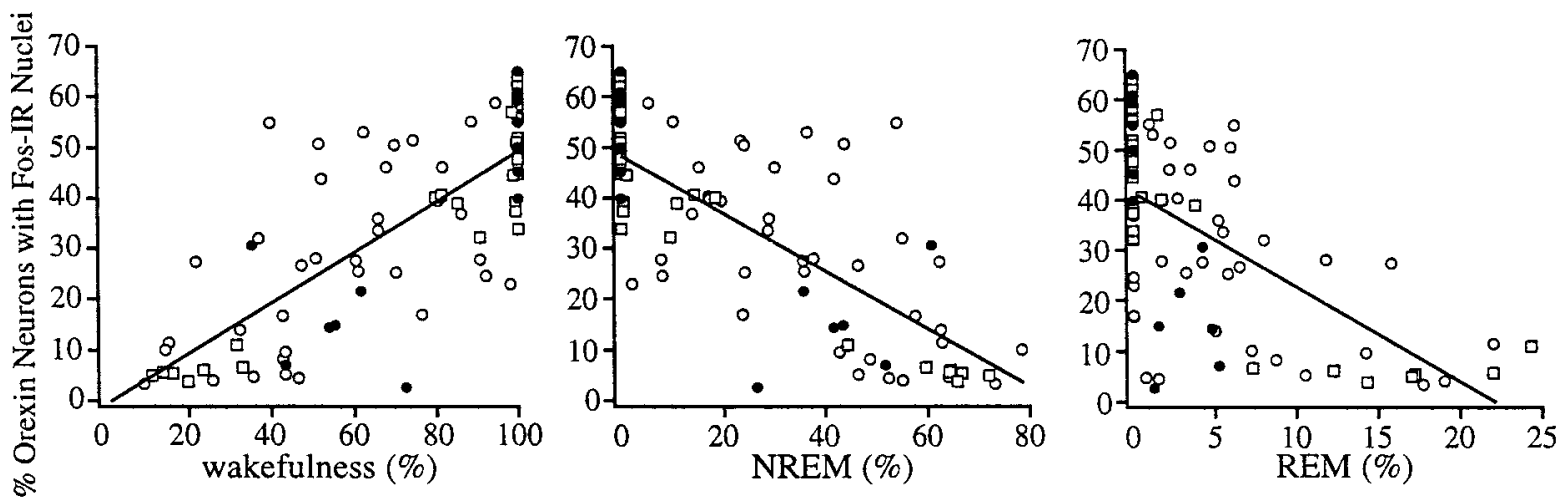

Figure 7. Across all three experiments, Fos expression in perifornical orexin-IR neurons correlates positively with the amount of wakefulness $(r=0.78$; $p<0.0001)$ and negatively with the amounts of NREM $(r=-0.78 ; p<0.0001)$ and REM sleep $(r=-0.63, p<0.0001)$. $\bigcirc$, Experiment $1 ; \bullet$, experiment $2 ; \square$, experiment 3 . 
and REM sleep, and decreased orexin signaling may allow the expression of sleep. Narcoleptic humans with a loss of orexin neurons (Peyron et al., 2000; Thannickal et al., 2000) and dogs with exon-skipping mutations of the OX2 receptor gene (Lin et al., 1999) have intrusions of REM sleep and REM-like behaviors into the waking period. Orexin knock-out mice have a similar dysregulation of REM sleep and also have increased amounts of REM and NREM sleep during the dark period (Chemelli et al., 1999). Thus, impaired orexin signaling may allow inappropriate expression of REM and NREM sleep. In normal individuals, physiologically decreased orexin signaling may allow the emergence of REM and possibly NREM sleep.

In experiments 1 and 3, orexin neuron activity correlated positively with body temperature and LMA over the $2 \mathrm{hr}$ preceding death. These associations are not surprising because wakefulness is associated with increases in $T_{\mathrm{b}}$ and LMA. Still, it remains possible that orexin neurons may play a role in the control of $T_{\mathrm{b}}$ and LMA, because Hagan and colleagues (1999) have demonstrated that intracerebroventricular injections of orexin-A increase LMA. Also, we cannot rule out the possibility that orexin neurons may influence other wake-associated behaviors such as eating and glucose regulation (Ida et al., 1999; Moriguchi et al., 1999; Sweet et al., 1999).

Fos expression in perifornical non-orexin-IR neurons also correlated with wakefulness, $T_{\mathrm{b}}$, and LMA and maintained a circadian pattern. Although some of these "non-orexin" neurons may simply have concentrations of orexin below our detection limit, most probably contain other neurotransmitters. Some of these neurons produce melanin-concentrating hormone $(\mathrm{MCH})$, a neuropeptide implicated in feeding and autonomic control (Elmquist et al., 1999). Like the orexin neurons, these $\mathrm{MCH}$ neurons innervate areas implicated in state control such as the tuberomammillary nucleus, suggesting a role in the control of behavioral state. However, we found no substantial diurnal variation in $\mathrm{MCH}$ neuron Fos expression (our unpublished data). The circadian variation in non-orexin neuron Fos probably occurs in other perifornical neurons such as those producing cocaine and amphetamine-regulated transcript, neurotensin, GABA, and glutamate, but the function of these cells is largely unknown. Some of these signaling molecules may influence behavioral state, but as yet, only orexin is clearly necessary for normal state control.

Our observation that orexin neurons are active during wakefulness fits well with several recent findings. Orexin fibers heavily innervate several wake-promoting nuclei such as the locus coeruleus, the dorsal raphe, and the tuberomammillary nucleus, and orexin increases the firing rate of locus coeruleus neurons. The sleep-wake behavior of orexin-deficient narcoleptic humans, orexin knock-out mice, and OX2 receptor-deficient dogs demonstrates that the orexin system is necessary to maintain wakefulness and suppress REM sleep. We have shown that orexin neurons are active during wakefulness, and these neurons may maintain or promote wakefulness by stabilizing or enhancing the activity of aminergic arousal regions. Conversely, decreased orexin neuron activity may be necessary for the production of sleep.

Further studies characterizing the factors that influence the activity of orexin neurons and defining how orexin is necessary for state regulation should greatly increase our understanding of the mechanisms underlying the control of sleep and wakefulness.

\section{REFERENCES}

Abrahamson E, Moore R (1999) Topographical organization of efferent projections arising from hypocretin (HC)-containing neuron populations located in the lateral hypothalamus. Soc Neurosci Abstr 25:1886.

Chemelli RM, Willie JT, Sinton CM, Elmquist JK, Scammell T, Lee C, Richardson JA, Williams SC, Xiong Y, Kisanuki Y, Fitch TE, Nakazato M, Hammer RE, Saper CB, Yanagisawa M (1999) Narcolepsy in orexin knockout mice: molecular genetics of sleep regulation. Cell 98:437-451.

Cirelli C, Tononi G (2000) On the functional significance of c-fos induction during the sleep-waking cycle. Sleep 23:453-469.

Date Y, Ueta Y, Yamashita H, Yamaguchi H, Matsukura S, Kangawa K, Sakurai T, Yanagisawa M, Nakazato M (1999) Orexins, orexigenic hypothalamic peptides, interact with autonomic, neuroendocrine and neuroregulatory systems. Proc Natl Acad Sci USA 96:748-753.

Edgar DM, Seidel WF (1997) Modafinil induces wakefulness without intensifying motor activity or subsequent rebound hypersomnolence in the rat. J Pharmacol Exp Ther 283:757-769.

Elmquist JK, Scammell TE, Jacobson CD, Saper CB (1996) Distribution of Fos-like immunoreactivity in the rat brain following intravenous lipopolysaccharide administration. J Comp Neurol 371:85-103.

Elmquist JK, Elias CF, Saper CB (1999) From lesions to leptin: hypothalamic control of food intake and body weight. Neuron 22:221-232.

Guillery RW, Herrup K (1997) Quantification without pontification: choosing a method for counting objects in sectioned tissues. J Comp Neurol 386:2-7.

Hagan J, Leslie R, Patel S, Evans M, Wattam T, Holmes S, Benham C, Taylor S, Routledge C, Hemmati P, Munton R, Ashmeade T, Shah A, Hatcher J, Hatcher P, Jones D, Smith M, Piper D, Hunter A, Porter R, Upton N (1999) Orexin A activates locus coeruleus cell firing and increases arousal in the rat. Proc Natl Acad Sci USA 96:10911-10916.

Ida T, Nakahara K, Katayama T, Murakami N, Nakazato M (1999) Effect of lateral cerebroventricular injection of the appetite-stimulating neuropeptide, orexin and neuropeptide $\mathrm{Y}$, on the various behavioral activities of rats. Brain Res 821:526-529.

Lin L, Faraco J, Li R, Kadotani H, Rogers W, Lin X, Qiu X, de Jong PJ, Nishino S, Mignot E (1999) The sleep disorder canine narcolepsy is caused by a mutation in the hypocretin (orexin) receptor 2 gene. Cell 98:365-376.

Moriguchi T, Sakurai T, Nambu T, Yanagisawa M, Goto K (1999) Neurons containing orexin in the lateral hypothalamic area of the adult rat brain are activated by insulin-induced acute hypoglycemia. Neurosci Lett 264:101-104.

Nishino S, Ripley B, Overeem S, Lammers GJ, Mignot E (2000) Hypocretin (orexin) deficiency in human narcolepsy. Lancet 355:39-40.

Peyron C, Tighe DK, van den Pol AN, de Lecea L, Heller HC, Sutcliffe JG, Kilduff TS (1998) Neurons containing hypocretin (orexin) project to multiple neuronal systems. J Neurosci 18:9996-10015.

Peyron C, Faraco J, Rogers W, Ripley B, Overeem S, Charnay Y, Nevsimalova S, Aldrich M, Reynolds D, Albin R, Li R, Hungs M, Pedrazzoli M, Padigaru M, Kucherlapati M, Fan J, Maki R, Lammers G, Bouras C, Kucherlapati R, Nishino S, Mignot E (2000) A mutation in a case of early onset narcolepsy and a generalized absence of hypocretin peptides in human narcoleptic brains. Nat Med 6:991-997.

Sakurai T, Amemiya A, Ishii M, Matsuzaki I, Chemelli RM, Tanaka H, Williams SC, Richardson JA, Kozlowski GP, Wilson S, Arch JR, Buckingham RE, Haynes AC, Carr SA, Annan RS, McNulty DE, Liu WS, Terrett JA, Elshourbagy NA, Bergsma DJ, Yanagisawa M (1998) Orexins and orexin receptors: a family of hypothalamic neuropeptides and $\mathrm{G}$ protein-coupled receptors that regulate feeding behavior. Cell 92:573-585.

Samson WK, Gosnell B, Chang JK, Resch ZT, Murphy TC (1999) Cardiovascular regulatory actions of the hypocretins in brain. Brain Res 831:248-253.

Scammell T, Estabrooke I, McCarthy M, Chemelli R, Yanagisawa M, Miller M, Saper C (2000) Hypothalamic arousal regions are activated during modafinil-induced wakefulness. J Neurosci 20:8620-8628.

Schwartz WJ, Takeuchi J, Shannon W, Davis EM, Aronin N (1994) Temporal regulation of light-induced Fos and Fos-like protein expression in the ventrolateral subdivision of the rat suprachiasmatic nucleus. Neuroscience 58:573-583.

Siegel JM (1999) Narcolepsy: a key role for hypocretins (orexins). Cell 98:409-412.

Sweet DC, Levine AS, Billington CJ, Kotz CM (1999) Feeding response to central orexins. Brain Res 821:535-538.

Taheri S, Sunter D, Dakin C, Moyes S, Seal L, Gardiner J, Rossi M, Ghatei M, Bloom S (2000) Diurnal variation in orexin A immunoreactivity and prepro-orexin mRNA in the rat central nervous system. Neurosci Lett 279:109-112.

Thannickal T, Moore RY, Nienhuis R, Ramanathan L, Gulyani S, Aldrich M, Cornford M, Siegel JM (2000) Reduced number of hypocretin neurons in human narcolepsy. Neuron 27:469-474. 